\title{
DESAIN MEJA BOARD GAME ULAR TANGGA UNTUK INTERAKSI SOSIAL PADA TUNANETRA STUDI KASUS SLB YPAB TEGALSARI SURABAYA
}

\author{
DESIGN TABLE BOARD GAME FOR SOCIAL INTERACTION IN \\ THE BLIND, CASE STUDY YPAB SLB TEGALSARI SURABAYA
}

\author{
Choirul Anam ${ }^{1}$, Muria Ilham Priharto \\ 1,2 Desain Produk, Fakultas Teknik Sipil dan Perencanaan, \\ Institut Teknologi Adhi Tama Surabaya, Jl. Arief Rahman Hakim No. 100 \\ Surabaya \\ 1choirul.choys@gmail.com, 2ilhammuria@gmail.com
}

\begin{abstract}
Abstrak : Individu Tunanetra mengalami keterbatasan kemampuan dalam berinteraksi sosial dengan individu lain, agar dapat berinteraksi dengan lingkungan, dibutuhkan orientasi dan mobilitas. Untuk itu diperlukan beberapa sarana dan prasarana pendidikan yang sesuai dengan kebutuhan para penyandang disabilitas tersebut, salah satu permaian yang cocok untuk melatih kemampuan orientasi dan mobilitas adalah permainan jenis board game.Penelitian ini bertujuan untuk mengatasi masalah sosial emosional yang buruk pada anak sekaligus untuk mengajak anak tunanetra ikut dalam bermain yang tidak lupa untuk mengedepankan estetika desain khusus bagi anak tunanetra. Hasil penelitian yang ditemukan merupakan hasil pengambilan data primer dari observasi kegiatan sehari-hari dari subjek sekaligus wawancara dengan subjek, guru, serta orang tua subjek dan data sekunder diperoleh dari hasil literasi dari sumber penelitian terkait. Metode penelitian yang digunakan adalah kualitatif deskriptif dengan mengkaji dari data primer dan data sekunder sehingga dalam produk tersebut ditemukan dari hasil gabungan analisis pola perilaku anak tunanetra dengan analisis desain, yakni material/bahan, bentuk, warna, serta system. Subjek penelitian diambil dari siswa SLB YPAB TEGALSARI SURABAYA. Pada hasil akhir maka ditemukan sebuh inovasi permainan tradisional yang terinspirasi dari papan catur yang sering dimainkan disekolah dan dimodifikasi menjadi board game ular tangga untuk tunanetra.
\end{abstract}

Kata kunci: Desain, Board game, Ular Tangga, Tunanetra.

Abstract : Blind individuals experience limited ability to interact socially with other individuals, in order to interact with the environment, orientation and mobility are required. For this reason, several educational facilities and infrastructure are needed that are in accordance with the needs of people with disabilities. One of the games that are suitable for training orientation and mobility skills is a board game. This study aims to overcome the bad social-emotional problems of children as well as to invite blind children to participate in playing and not forget to prioritize a special design aesthetic for blind children. The research results found are the results of primary data collection from observations of daily activities of the subject as well as interviews with the subject, teacher, and subject's parents and secondary data obtained from literacy results from related research sources. The research method used is to examine primary data and secondary data so that in finding these products it is found from the combined results of the analysis of the behavior patterns of blind children with design analysis, namely material / material, shape, color, and system. Research subjects were taken from students of SLB YPAB TEGALSARI SURABAYA. In the final result, a traditional game innovation is found that is inspired by a chess board that is often played in schools and modified into a snake and ladder board game for the blind.

Keywords: Design, Board game, Snakes and Ladders, Blind 


\section{PENDAHULUAN}

Permainan adalah suatu kegiatan yang bertujuan untuk menghilangkan kejenuhan atau hanya sebagai kesenangan belaka. Permainan seringkali dilakukan oleh anak-anak untuk mengisi waktu luang dikesehariannya (Fatturaman 2019). Dikatakan bahwa permainan memiliki peran penting dalam proses tumbuh kembang anak. Permainan sendiri memiliki pengaruh pada perkembangan anak karena permainan mampu menstimulasi aspek motorik, pola pikir, sosial emosional, serta bahasa anak(Khasanah, Prasetyo, and Rakhmawati 2011). Pendapat tersebut juga dipaparkan oleh (Agus and Wahyuni 2018) bermain pada usia prasekolah telah terbukti mampu meningkatkan perkembangan mental, kecerdasan, daya pikir anak terangsang untuk mengembangakan aspek emosional, sosial, serta fisik anak. Terlihat banyak beberapa orang tua memberikan sebuah edukasi kepada anak lewat media yang mereka sukai yaitu permainan. Pemberian edukasi ini telah lama dilakukan oleh orang tua lewat permainan tradisional, permainan tradisional sendiri dapat dikatakan permainan rakyat karena memiliki sifat menghibur diri serta mampu memunculkan efek rekreatif dan kenyamanan sosial (Hasanah 2016). Terlihat memiliki efek menghibur diri, permainan tidak hanya digemari anak kecil, permainan juga masih digemari oleh sebagian orang dewasa.

Seiring dengan berjalannya waktu permainan tradisional mampu berkembang sesuai dengan perkembangan teknologi. Hal ini terlihat mainan tradisional dapat digeser oleh permainan elektronik, yang dimainkan dengan perantara konsol tertentu seperti playstation, xbox, game online dan banyak permainan lain yang dapat dengan mudah diunduh melalui gadget. Adanya fenomena tersebut bayak orang tua mengeluhkan bahwa anak mereka telah kecanduan bermain game online. Game online sendiri memberikan pengalaman menantang sekaligus menarik, sehingga para pemain rela memberikan waktu lebih demi kepuasan (Febriandari and Nauli 2016). Dijelaskan pula oleh (Weinstein 2014) bahwa pemain game online akan bermaian secara berlebihan, hal ini juga yang akan menimbulkan pengaruh negatif pada diri pemaian. Pada saat kecanduan dalam bermain game online, atas penuturan dari orang tua mereka mampu menghabiskan sejumlah uang, hanya untuk dapat bermain game online. Dampak buruk lain yang mucul adalah anak sulit sekali untuk melakukan sosialisasi dengan teman sebayanya. Kasus tersebut mendorong untuk pengembalian permainan tradisional, agar anak mampu melakukan sosialisasi dengan teman sebayanya.

Pada kasus tersebut menunjukkan bahwa visual dari permainan yang disajikan membuat para pengguna merasa lebih tertarik dalam bermain. Bentuk visual merupakan informasi yang mudah diterima oleh otak, sekitar $75 \%$ hingga $87 \%$ informasi yang didapat seseorang diperoleh lewat visual yakni mata, sisanya yakni 13\% hingga 25\% disalurkan dari indera lainya (Wahyuni 2017). Adanya kasus tersebut juga, maka permainan tradisional perlu mendapat sentuhan kemasan baru agar terlihat modern sekaligus dapat menarik para pengguna lewat visual yang ditampilkan. Bentuk visual dari permainan memang menjadi fokus utama dalam pembuatan sebuah permainan, namun tetap memunculkan fungsi utama yakni manfaat dari permainan tradisional sebagai media edukasi, berhubungan sosial, serta efek rekreatif bagi penggunanya. Pengembalian permainan tradisional yang memiliki visual menarik diharapkan dapat mengatasi permasalahan pada anak, namun jika fungsi utama visual yang lebih ditonjolkan maka permainan tersebut belum ramah 
untuk semua kalangan. Disebut belum ramah karena fungsi visual ini sulit dan bahkan tidak dapat dirasakan oleh anak-anak atau seseorang yang memiliki kebutuhan khusus, seperti tunanetra.

Tunanetra adalah individu tidak berfungsi sempurna yang indera penglihatannya (kedua- duanya) sebagai saluran penerima informasi dalam kegiatan sehari-hari seperti halnya orang awas. Tunanetra memiliki ketajaman penglihatannya (visusnya) kurang dari 6/21 (hanya dapat membaca huruf dari jarak 6 meter yang mampu di baca dari jarak 21 meter oleh orang normal). Oleh karena itu tunanetra dibagi menjadi dua. Pertama buta, jika sama sekali tidak mampu menerima rangsangan dari luar visus. Kedua low vision, bila ketajaman penglihatannya kurang dari 6/2, menurut Somantri (dalam Camalia, Susanto and Susilo, 2016). Adanya keadaan tersebut seseorang yang mengalami tunanetra pada saat melakukan orientasi dan mobilitas mengandalkan indera lain untuk memahami kegiatan atau lingkungannya, indera tersebut meliputi penciuman, pendengaran, dan juga perabaan (Rahmawati and Sunandar 2018). Individu Tunanetra mengalami keterbatasan kemampuan dalam berinteraksi sosial dengan individu lain, agar dapat berinteraksi dengan lingkungan, dibutuhkan orientasi dan mobilitas. Untuk itu diperlukan beberapa sarana dan prasarana pendidikan yang sesuai dengan kebutuhan para penyandang disabilitas tersebut (Munawaroh and Aisyah 2019) salah satu permaian yang cocok untuk melatih kemampuan orientasi dan mobilitas adalah permainan jenis board game.

Board game merupakan salah satu media hiburan yang melibatkan interaksi sosial di dalamnya (Gede et al. 2016). Sedangkan menurut (Mike Scorviano dalam Mubarak, 2012) board game adalah jenis permainan di mana alat-alat atau bagian-bagian permainan ditempatkan, dipindahkan, atau digerakkan pada permukaan yang telah ditandai atau dibagi-bagi menurut seperangkat aturan. Permainan mungkin didasarkan pada strategi murni, kesempatan, atau campuran dari keduanya dan biasanya memiliki tujuan yang harus dicapai. Board game dikatakan salah satu media yang dapat digunakan untuk belajar, karena board game mampu merangsang kemampuan auditori, yang terlihat dari penjelasan aturan permainan dan kinestetik dimana seseorang akan lebih mudah paham karena ada bantuan menyentuh wujud board game, sekaligus interaksi langsung sehingga informasi tertentu mudah untuk diingat (Romanica 2018) Board game memiliki beberapa jenis salah satunya adalah ular tangga. Menurut Zuhdi dalam (Wiranda 2020) permainan ular tangga merupakan salah satu jenis permainan kompetisi yang dapat menumbuhkan kemampuan kerjasama antar siswa sehingga untuk merekayasa pengalaman sosial dan moral anakanak. Setiap keputusan pada desain dapat berpotensi meliputi atau mengecualikan pengguna, dalam perancangannya peneliti menggunakan konsep accessible atau biasa disebut dengan istilah inclusive design, menekankan pada kontribusi untuk lebih memahami keberagaman pengguna sehingga sebuah desain dapat mengakomodasi sebanyak-banyaknya pengguna. Keberagaman pengguna meliputi bagaimana kapasitasnya, kebutuhannya, dan aspirasinya (University of Cambridge dalam Pradipta, 2016).

Oleh karena itu tujuan dari penelitian ini adalah merancang board game ular tangga untuk mengembangkan sosial emosional pada tunanetra, dari penelitian sebelumnya ditemukan hasil bahwa suatu media permainan dapat membantu seorang tunanetra bersosialisasi dengan teman sebaya. 


\section{KASUS STUDI \& METODE PENELITIAN}

Lokasi penelitian ini berada di SLB A YPAB Jl. Tegalsari 56, Kedungdoro, Kec. Tegal Sari, Surabaya, dan untuk objek yang digunakan dalam penelitian ini yaitu permainan yang dimainkan oleh anak tuna netra yang berada di SLB A YPAB Jl. Tegalsari.

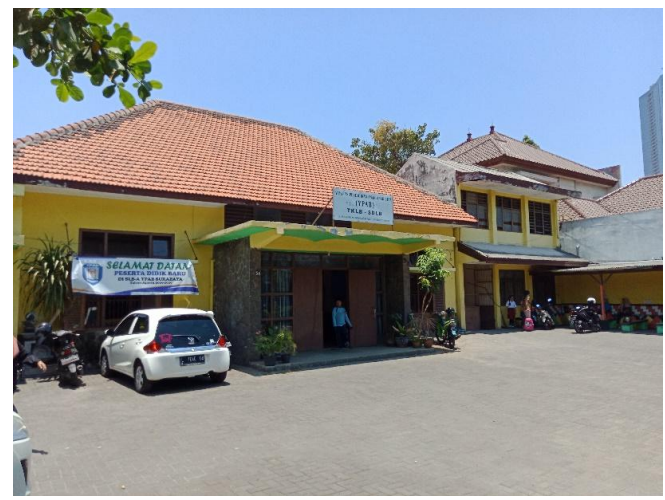

Gambar 1. SLB A YPAB J1. Tegalsari 56, Kedungdoro

Metode yang digunakan dalam penelitian ini menggunakan metode kualitatif deskriptif dengan kajian data primer yaitu melakukan wawancara dan observasi secara langsung, dan juga akan menggunakan data sekunder berupa literatur seperti buku, jurnal, artikel ilmiah dan sumber-sumber terkait, dimana data yang diperoleh akan digunakan sebagai bahan analisis dan diaplikasikan terhadap sebuah desain.

\section{HASIL DAN TEMUAN}

Adanya hasil wawancara dan observasi yang telah diambil dari 10 orang responden terpilih, yaitu orang tua, guru, dan siswa tunanetra. Observasi yang telah dilakukan meliputi, analisa material, warna, bentuk, sistem, ergonomi, kebutuhan hingga pada hasil kesimpulan pada rancangan produk meja board game ular tangga untuk interaksi sosial tunanetra, dapat dijabarkan sebagai berikut.

\subsection{Warna}

Hasil tahap akhir dari analisis warna yang didapat untuk produk meja terpilih menggunakan warna natural dari kayu, dan untuk board game ular tangga menggunakan warna-warna cerah serta kontras, dikarenakan ada 2 jenis kebutaan yaitu blind dan low vision, pemberian warna sendiri digunakan untuk tunanetra low vision karena jenis ini masih dapat melihat walau pengglihatannya tidak maksimal seperti orang normal.

\subsection{Material}

Hasil tahap akhir pada material yang telah dilakukan menunjukkan bahwa produk meja menggunakan material kayu FJL, material kayu diambil seagai bahan pemuatan meja karena memiliki struktur yang kuat dan kokoh. Sedangkan untuk board game ular tangga menggunakan material gabungan dari busa hati dan plat besi $1 \mathrm{~mm}$ sebagai material utama, dan untuk material bidak menggunakan 3D print. Untuk material ular tangga sendiri menggunakan plat karena permainan ini menggunakan sistem rekat magnet sehingga bidak akan menempel dengan plat besi tersebut, penggunaan $3 \mathrm{~d}$ 
print sebagai bidak dengan alasan $3 \mathrm{~d}$ print adalah material yang customize atau mudah untuk dibentuk.

\subsection{Bentuk}

Pada bagian bentuk produk board game ular tangga untuk tunanetra, hasil akhir menunjukksan bentuk persegi dengan ukuran $30 \times 30 \times 1 \mathrm{~cm}$. Dan untuk meja memiliki bentuk persegi panjang dengan ukuran $45 \times 30 \times 28 \mathrm{~cm}$.

\subsection{Sistem}

Pada hasil akhir pembuatan produk meja board game ular tangga untuk tunanetra menunjukan hasil sistem portable, meja menggunakan sistem portable karena peneliti bertujuan membuat meja yang dapat dibawa dan digunakan dimana saja.

\subsection{Ergonomi}

Pada hasil analisis bagian egronomi untuk produk meja permainan ular tangga multifungsi untuk tunanetra, disesuaikan bentuk agar mudah dijangkau tangan dari anak usia 8-10 tahun

\subsection{Kebutuhan}

Adapun kebutuhan khusus yang telah dianalisis untuk produk meja board game ular tangga untuk tunanetra, menggunakan konsep accessible dengan menggunakan braille dan dadu bersuara untuk mempermudah tunanetra memainkannya.

\section{DISKUSI/PEMBAHASAN}

Penelitian ini mengusung judul desain meja board game ular tangga untuk tunanetra studi kasus SLB YPAB Tegalsari Surabaya, pembahasan pertama yakni pada pemilihan untuk membuat inovasi baru dengan membuat ulang produk permainan tradisonal, karena untuk menjawab permasalahan yang dirasakan orang tua pada zaman sekarang. Masalah tersebut yakni berupa kemampuan sosial emosional pada anak yang buruk, oleh karna itu membangkitkan permainan tradisional kembali adalah salah satu cara yang dapat diambil.

Pada pemilihan tunanetra sendiri sebagai subjek penelitian, hal ini dirasa bahwa keindahan dari desain pada umumnya mendapat kesan pertama menarik lewat kesan pertama melihat warna dan bentuk yang dipakai. Keadaan ini hanya dapat dirasakan oleh mereka yang tidak memiliki keterbatasan dalam melihat, lain halnya dengan mereka yang dapat melihat. Adanya estetika desain khusus harus diperhatikan agar mereka yang mengalami ketunanetraan mampu merasakn keindahan desain yang sama dirasakan oleh layaknya orang normal lainya, dua keistimewaan pembuatan produk ini yakni bertujuan untuk mengatasi masalah sosial emosional yang buruk yang dialami oleh anak jaman sekarang sekaligus dapat mengajak anak tunanetra ikut dalam bermain yang tidak lupa untuk mengedepankan estetika desain khusus bagi anak tunanetra.

Metode perancangan meja board game ular tangga untuk interaksi sosial tunanetra adalah sebagai berikut : 


\subsection{Alternatif Desain dan Final Desain}

Berikut adalah beberapa alternatif desain meja board game ular tangga untuk interaksi sosial tunanetra

Tabel 1. Alternatif Desain Meja
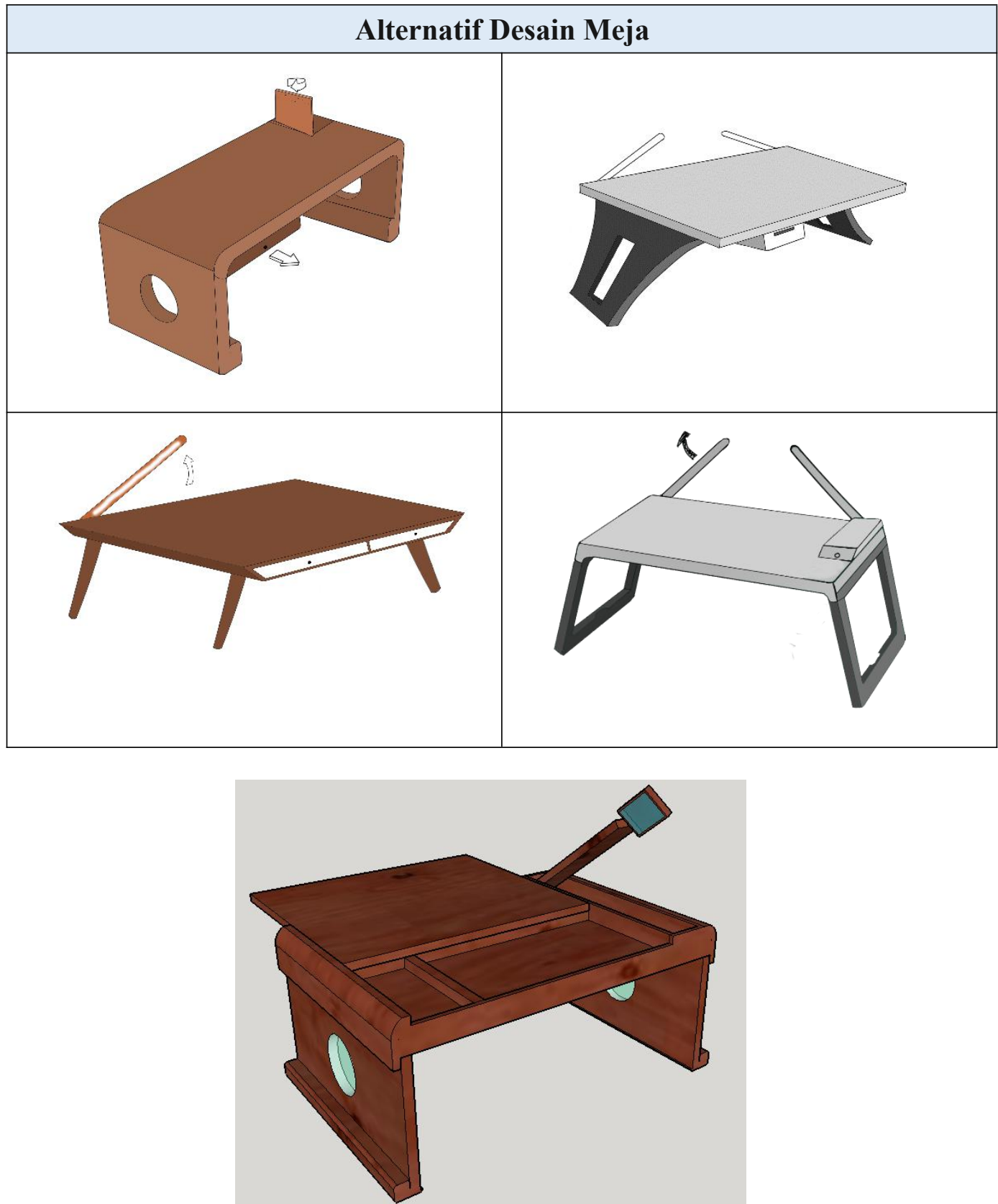

Gambar 2. Desain Final Meja

Dari alternatif desain diatas dipilih 1 desain dan akan dikembangkan menjadi desain final, berikut adalah desain final dari meja : 


\subsection{Desain Board game Ular Tangga}

Berikut adalah desain board game ular tangga yang menggunakan konsep accessible dilengkapi dengan angka braille, dadu berbasis suara serta bidak timbul yang dapat diraba, agar memudahkan anak tunanetra memainkannya
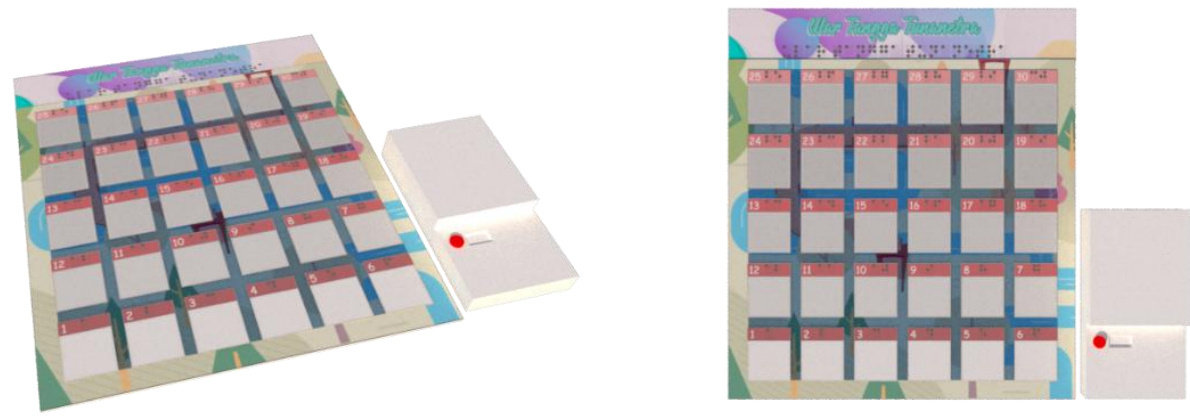

Gambar 3. Desain Board game Ular Tangga Tunanetra

\subsection{Proses Test Prototype dan Validasi}

Ini adalah proses ujicoba produk pada subjek secara langsung, dan akan dilihat bagaimana produk digunakan secara langsung dan juga dilakukan validasi dengan guru terkait sehingga produk benar-benar layak untuk dimainkan oleh tunanetra

Hasil setelah melakukan proses uji coba kepada pengguna didapatkan hasil bahwa interaksi sosial pada tunanetra mengalami peningkatan dari yang sebelumnya kurang bahkan kesulitan menjadi terbantu karena adanya media yang digunakan untuk bermain bersama, pengguna mulai penasaran dan tertarik untuk memainkannya lebih lanjut dan bahkan sampai mengajak teman yang lain ikut bermain bersama, sedangkan untuk pembimbing menjadi lebih mudah mengarahkan anak didiknya dengan melatih keterampilan sosial emosional mereka agar kelak dapat mudah bergaul dan sosialisasi dilingkungan yang baru dan mendapat media baru sebagai bahan ajar di sekolah tersebut.
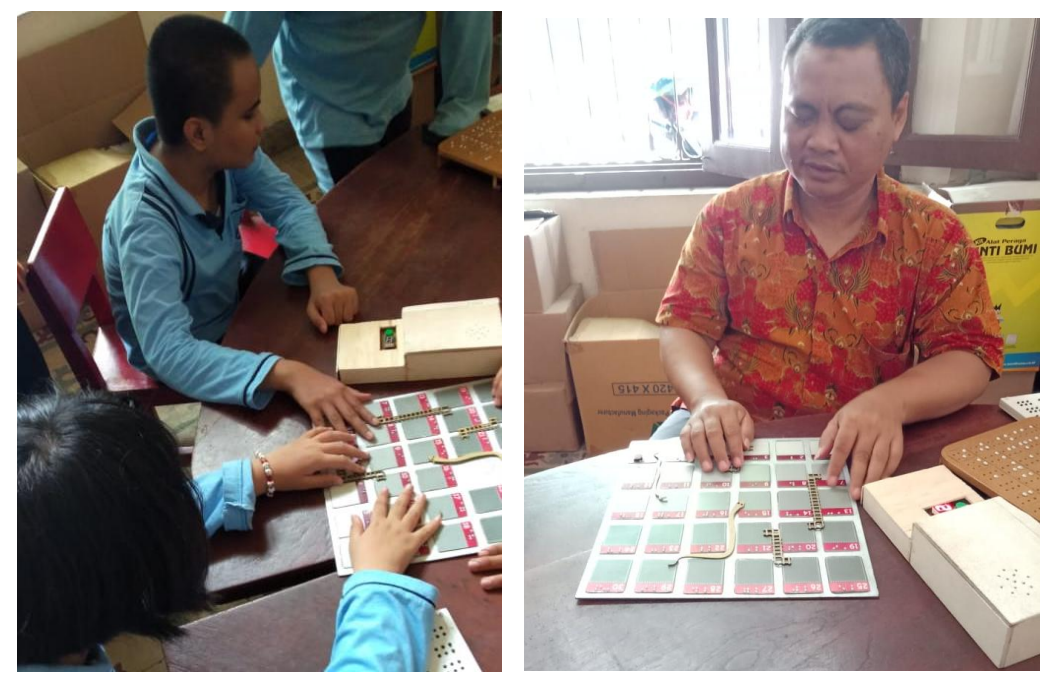

Gambar 4. Percobaan dan Validasi kepada anak dan guru tunanetra 


\subsection{Hasil Akhir Produk}

Produk sudah melewati tahap ujicoba dan perbaikan sehingga sampai pada tahap akhir. Desain dari permainan ular tangga menggunakan sistem yang accessible atau ramah terhadap penyandang disailitas sehingga para tunanetra dengan mudah memainkannya. Secara kesesluruhan fungsi dari produk tersebut dapat digunakan dengan baik oleh tunanetra mulai dari permainan sampai pengaplikasian meja.
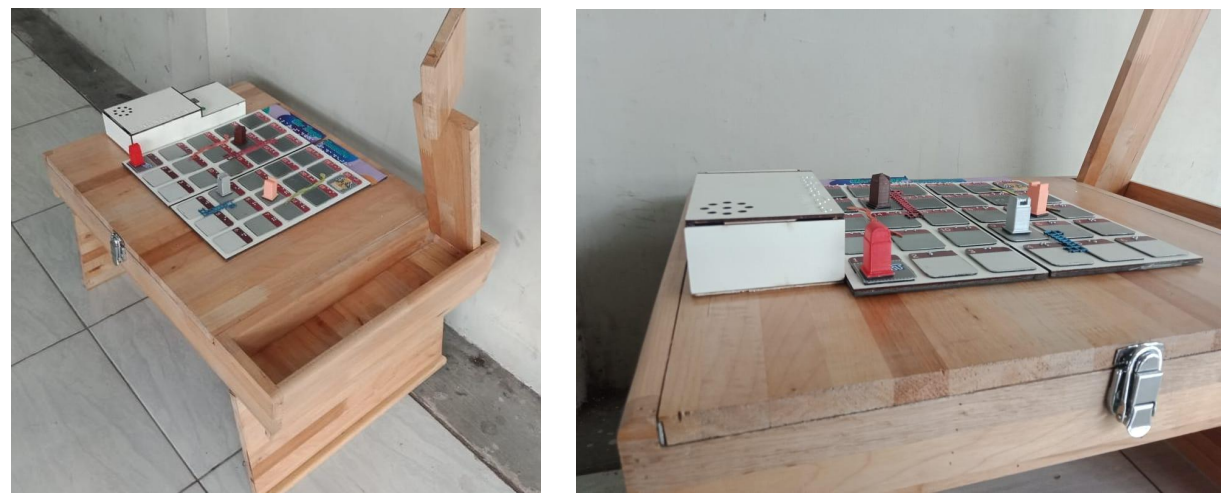

Gambar 5. Hasil Akhir Produk Meja Board game Untuk Interaksi Sosial Tunanetra

\section{KESIMPULAN}

Hasil penelitian yang telah dilakukan peneliti dapat disimpulkan bahwa anak penyandang tunanetra memiliki kekurangan dalam sosial emosional yang dapat menghambat tumbuh kembang penyandang tunanetra, dengan dibuatnya produk meja board game untuk interaksi sosial tunanetra, para penyandang tunanetra merasa terbantu khususnya anak-anak tunanetra yang masih ditahap perkembangan dan butuh pendampingan lebih. Dalam analisis dikemukakan bahwa desain dari permainan ular tangga menggunakan sistem yang accessible atau ramah terhadap penyandang disailitas sehingga para tunanetra dengan mudah memainkannya. Secara kesesluruhan fungsi dari produk tersebut dapat digunakan dengan baik oleh tunanetra mulai dari permainan sampai pengaplikasian meja. Namun kekurangan dari produk ini terletak pada ukuran dan bobot meja yang besar dan berat untuk anak-anak sehingga perlu bantuan orang dewasa untuk memaanya, hal ini disebabkan oleh keterbatasan bahan yang mampu diperoleh oleh peneliti.

\section{DAFTAR PUSTAKA}

Agus, Tunggul Sri, and Hesti Wahyuni. 2018. "STIMULASI PERMAINAN PUZZLE BERPENGARUH TERHADAP PERKEMBANGAN SOSIAL DAN KEMANDIRIAN ANAK USIA PRASEKOLAH" 1: 62-77.

Camalia, Fayeza, Hadi Susanto, and Susilo. 2016. "PENGEMBANGAN AUDIOBOOK DILENGKAPI ALAT PERAGA MATERI GETARAN DAN GELOMBANG UNTUK TUNANETRA KELAS" 5 (2).

Fatturaman, Umar Farouq. 2019. "PERANCANGAN INTERIOR PUSAT PERMAINAN TRADISIONAL JAWA BARAT." 
Febriandari, Dona, and Fathra Annis Nauli. 2016. "HUBUNGAN KECANDUAN BERMAIN GAME ONLINE TERHADAP IDENTITAS DIRI REMAJA" 4 (1): 50-56.

Gede, Dewa, Dayananda Mastra, Patra Aditia, Program Studi, Desain Komunikasi, Fakultas Industri Kreatif, and Universitas Telkom. 2016. "PERANCANGAN BOARD GAME SEBAGAI MEDIA EDUKASI PENYAKIT PADA DESIGN OF BOARD GAME AS AN EDUCATIONAL MEDIA FOR DISEASE ON" 3 (3): 889-96.

Hasanah, Uswatun. 2016. "Pengembangan Kemampuan Fisik Motorik Melalui Permainan Tradisional Bagi Anak Usia Dini," 717-33.

Khasanah, Ismatul, Agung Prasetyo, and Ellya Rakhmawati. 2011. "Jurnal Penelitian PAUDIA, Volume 1 No. 1 2011" 1 (1): 91-105.

Mubarak, Abdul. 2012. "BOARD GAME PAHLAWAN KEMERDEKAAN."

Munawaroh, Ai Siti, and Siti Aisyah. 2019. "KAJIAN RUANG SEKOLAH LUAR BIASA ( SLB ) DHARMA BAKTI DHARMA PERTIWI LAMPUNG STUDY OF DHARMA BAKTI DHARMA PERTIWI SLB IN LAMPUNG Standar Sarana Prasarana Untuk Sekolah Dasar Luar Biasa ( SDLB ), Sekolah Menengah" 4 (2): 143-58.

Pradipta, Adith Widya. 2016. "DESAIN JAM TANGAN KAYU DENGAN KONSEP JUJUR MATERIAL DAN INKLUSIF."

Rahmawati, Rika Yulia, and Asep Sunandar. 2018. "Peningkatan Keterampilan Orientasi Dan Mobilitas Melalui Penggunaan Tongkat Bagi Penyandang Tunanetra" 4 (November): 100-103.

Romanica, Gladis Mega. 2018. "PERANCANGAN BOARD GAME BERTEMA PASAR TRADISIONAL YOGYAKARTA."

Wahyuni, Resa. 2017. "BUKU GIZI BRAILLE SEBAGAI MEDIA PENDIDIKAN UNTUK MENINGKATKAN PENGETAHUAN ANAK TUNANETRA" 1 (1): 59-64.

Weinstein, Aviv Malkiel. 2014. "Computer and Video Game Addiction - A Comparison between Game Users and Computer and Video Game Addiction - A Comparison between Game Users and Non-Game Users," no. May. https://doi.org/10.3109/00952990.2010.491879.

Wiranda, Agus. 2020. "Belajar, Analisis Media Pembelajaran Ular Tangga Dengan Menggunakan Model Pembelajaran Kooperatif Tipe STAD Dalam Meningkatkan Minat." 